\title{
Facile synthesis of hydroxyapatite nanoparticles by a polymer-assisted method: morphology, mechanical properties and formation mechanism
}

\author{
Gamagedara $\mathrm{TP}^{1,2,3 *}$, Rathnayake $\mathrm{UM}^{2}$ and Rajapakse $\mathrm{RMG}^{1,2}$ \\ ${ }^{1}$ Post Graduate Institute of Science, University of Peradeniya, Peradeniya, Sri Lanka \\ ${ }^{2}$ Deparment of Chemistry, Faculty of Science, University of Peradeniya, Peradeniya, Sri Lanka \\ ${ }^{3}$ Department of Basic Science, Faculty of Allied Health Sciences, University of Peradeniya, Peradeniya, Sri Lanka
}

\begin{abstract}
Synthetic hydroxyapatite (HA), is emerging as the most promising bioceramic material for orthopaedic applications due to its similarity to the inorganic matrix of living bone and teeth. The miniaturization of size and tuning of the morphology are an important factor for current biomedical research. Polymers are useful components in the formation of one- and zero-dimension nanosized materials. Rod-like assemblies of HA spherical nanoparticles of $\sim 20$ nm with nanopores can be

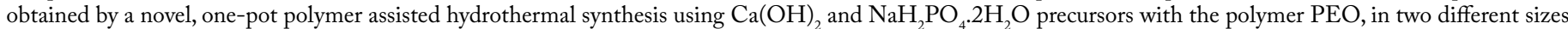
without controlling the $\mathrm{pH}$ manually. The effect of the amount and the molecular weight of the polymer, mechanical properties and morphology were studied, and formation mechanism was proposed. The conclusion is supported by the results from X-ray diffractometry (XRD), Fourier transforms infrared (FTIR) spectroscopy and scanning electron microscopy (SEM). With increasing the PEO content in the precursor solution, particle size can be decreased, and Young's modulus can be increased. The Young's modulus of HA synthesized using PEO are comparable with that of natural cortical bone. In addition, synthesized HA can be used as a biomaterial due to its uniform morphology, highly disperse particles of nano size and nanoporosity.
\end{abstract}

\section{Introduction}

Synthetic HA, having the chemical formula, $\mathrm{Ca}_{10}\left(\mathrm{PO}_{4}\right)_{6}(\mathrm{OH})_{2}$, is emerging as the most promising bioceramic material for orthopaedic applications because of its similarity in chemical structure to that of the inorganic matrix of living bone and teeth [1-3]. Calcium phosphate biomaterials, mainly HA, find many clinical applications in the repair of bone defects, bone augmentation and coating for metal implants. HA is a polar hexagonal and highly anisotropic crystal that naturally grows into a 1D nanostructure [4]. Nanostructured HA possesses higher specific surface areas that enhance the adhesion of cells, proteins, and drugs [5-7]. Hence, the miniaturization of size and tuning of the morphology are an important factor for current biomedical research [8-11]. Mimicking the process of biomineralization has led to the development of biomolecule mediated synthesis of nanoparticles that conquers many of the problems associated with nanoparticle synthesis [12]. The use of macromolecules as a templating agent to manipulate the growth of inorganic crystals has been realized in many biological systems [13-15]. Many previous reports have shown that polymers such as PEG (poly(ethylene glycol)), PVP (polyvinyl pyrrolidone), and PAM (polyacrylamide) are useful components in the formation of one- and zero-dimension nanosized materials[13,15]. The use of macromolecules as a templating agent to manipulate the growth of inorganic crystals has been done in many biological systems. Many previous reports show that polymers such as PEG (poly(ethylene glycol))[16] (Figures 1-3), PVP (polyvinyl pyrrolidone)[17], and PAM (polyacrylamide) are useful components in the formation of one- and zero-dimension nanosized materials. Some studies have investigated the preparation
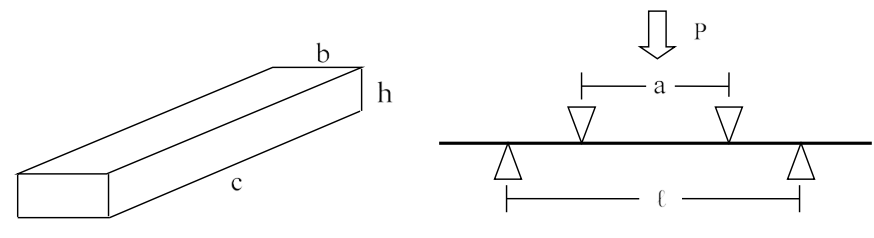

Figure 1. The 4-point bending configuration (a) sample (b) the whole set up

of nanomaterials such as $\mathrm{ZnO}[16], \mathrm{MoO}_{2}$ whiskers, and $\mathrm{Al}_{2} \mathrm{O}_{3}-\mathrm{TiO}_{2}$ composite nanoparticles using polymer-assisted synthesis[15]. In another study [15], Flower-like HA nanostructures were synthesized by a polymer-assisted hydrothermal method. Although there are several types of research carried out on the basis of polymer assisted synthesis of HA using different polymers under mild conditions $[13,15]$, mechanical properties of prepared HA and effect of the amount and molecular weight of the polymer were not studied. Therefore, in this study, polymer assisted hydrothermal synthesis of nano-HA was done using PEO as the templating agent. The effect of the amount and the molecular weight of the polymer, mechanical properties and morphology were studied, and the formation mechanism was proposed.

${ }^{\star}$ Correspondence to: Gamagedara TP, Department of Basic Science, Faculty of Allied Health Sciences, University of Peradeniya, Peradeniya, Sri Lanka, E-mail: tpiumnil@pdn.ac.lk

Key words: hydroxyapatite, nanoparticles, polymer-assisted synthesis, polyethylene oxide

Received: May 11, 2018; Accepted: May 18, 2018; Published: May 22, 2018 

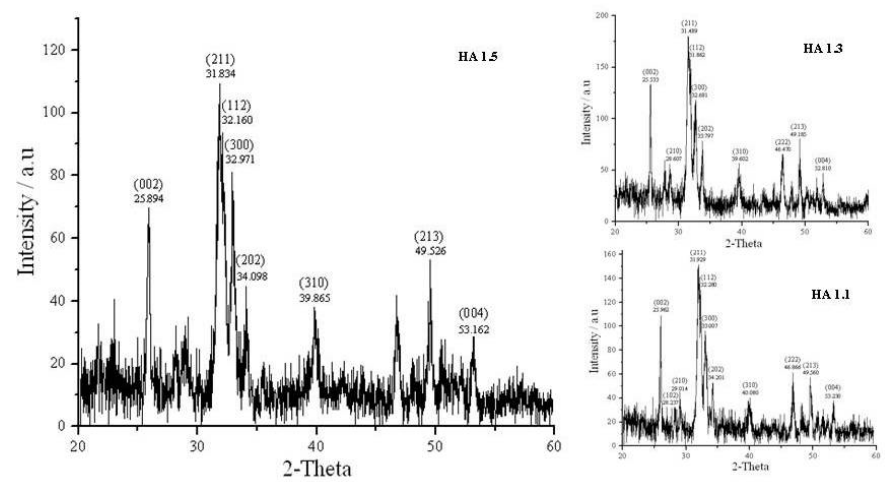

Figure 2. XRD diffraction patterns of HA of series 01 (Sample synthesis mediated by $4 \mathrm{X} 10^{6} \mathrm{Da} \mathrm{PE}$
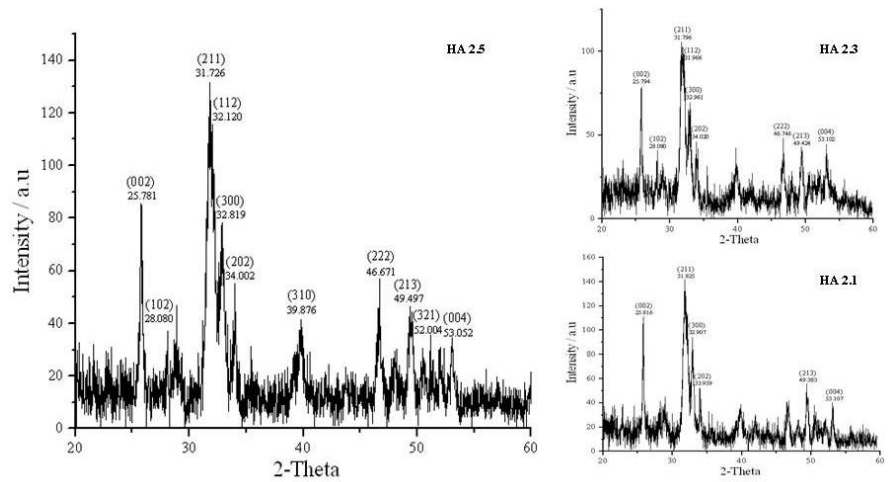

Figure 3. XRD diffraction patterns of HA of series 02 (Sample synthesis mediated by $\left.6 \mathrm{X} 10^{6} \mathrm{Da} \mathrm{PEO}\right)$

\section{Materials and methods}

All chemicals were of analytical grade and were used without further purification. Materials used in this synthesis were calcium hydroxide $\left(\mathrm{Ca}(\mathrm{OH})_{2}\right)$, sodium dihydrogen phosphate $\left(\mathrm{NaH}_{2} \mathrm{PO}_{4} \cdot 2 \mathrm{H}_{2} \mathrm{O}\right)$, polyethene oxide (MW 4,000,000 Da and MW 6,000,000 Da) and ethanol (98\%). De-ionized water is used throughout the experiment. First, PEO $(0.500 \mathrm{~g})$ was added to $50 \mathrm{~mL}$ of de-ionized water and kept in a water bath at $40^{\circ} \mathrm{C}$ while stirring until all PEO got dissolved. Then $\mathrm{Ca}(\mathrm{OH})_{2}(1.219 \mathrm{~g})$ was slowly added while stirring to get a homogeneous mixture. Next $\mathrm{NaH}_{2} \mathrm{PO}_{4} \cdot 2 \mathrm{H}_{2} \mathrm{O}(1.548 \mathrm{~g})$ was dissolved in $50 \mathrm{~mL}$ of deionized water to obtain a clear phosphate solution, which was added drop-wise to the above $\mathrm{PEO}$ containing $\mathrm{Ca}(\mathrm{OH})_{2}$ solution. The mixture was then stirred for 24 hours at room temperature. Next, the produced milky gel suspension was transferred into a Teflon-lined stainless-steel autoclave and autoclaved at $140^{\circ} \mathrm{C}$ for 3 hours. The resultant suspension was filtered off and washed repeatedly with de-ionized water and ethanol respectively. Finally, the sample was dried at $120^{\circ} \mathrm{C}$ for 24 hours. The control samples (HA 1.1 and HA 2.1) were synthesized without adding $\mathrm{PEO}$ using the same procedure as described above. Tables 1 and 2 show the amounts of starting materials (maintaining Ca:P ratio $=1.67: 1.00$ ) used in the synthesis of HA samples of series 01 and 02 together with sample identification names.

Mechanical Properties: Mechanical properties of the materials, such as the flexural strength (Modulus of Rupture, MOR), Young's Modulus (Y) were explored using a locally made universal mechanical testing machine with 4-point bending at a crosshead speed of $4.075 \mathrm{X}$ $10^{-3} \mathrm{mms}^{-1}$ (Figure 1). In the case of 4-point bending, the MOR can be calculated according to the following equation (1):

$$
\operatorname{MOR}_{(4-p o i n t)}=\frac{3(l-a) P}{2 b h^{2}}(1)
$$

Where,

b,c,h-Dimensions of the bar [breadth, length, and height respectively]

a-Inner distance of the four-point bending setup $(1 \mathrm{~cm})$

$\ell$-Outer distance of the four-point bending setup $(2 \mathrm{~cm})$

P-Force at breaking point

Young's Modulus (Y) was calculated by the following equation (2).

$$
Y=\frac{\text { Tensile Stress, } \sigma}{\text { Tensile Strain, } \varepsilon}=\frac{3(l-a) P / 2 b h^{2}}{6 h x /(1-a)(1+2 a)} \text { (2) }
$$

Where, $\mathrm{x}=$ depression at the load point.

$X$-ray diffraction (XRD) spectra were recorded using computercontrolled X-ray diffractometer (Seimens D 5000, Cu $\mathrm{K}_{\alpha}$ radiation, $\lambda$ $=0.1540562 \mathrm{~nm}, 18 \mathrm{~kW}$ rotating anode) (University of Peradeniya, Sri Lanka) and XRD analysis was done at $40 \mathrm{kV}$ and $25 \mathrm{~mA}$ with a scanning rate of $1^{\circ} \mathrm{min}^{-1}$. For this study, powdered forms of the samples were used, and Stainless steel was analyzed as it is. Particle size was obtained using the Debye-Scherer formulae (3).

$$
\mathrm{D}=\frac{\mathrm{k} \lambda}{\beta \cos \theta}
$$

Where;

D- Median size of the particle

K- Broadening constant (varying between 0.89 to 1.39 )

$\lambda$ - Wave length of $\mathrm{Cu} \mathrm{Ka}$ radiation $(\lambda=1.54060 \AA)$

$\beta$ - Full width at half maximum intensity (in radians) (FWHM)

$\theta$ - Position of peak maximum

Fourier Transform Infrared Spectroscopy (FTIR): The FTIR spectra

Table 1. Amounts of starting materials used in the synthesis of HA samples of series 01

\begin{tabular}{|c|c|c|c|}
\hline \multirow{2}{*}{ Sample Name } & \multicolumn{3}{|c|}{ Weight (moles) / g } \\
\cline { 2 - 4 } & $\begin{array}{c}\text { PEO } \\
\text { of 4,000,000 Da }\end{array}$ & NaH $_{2} \mathbf{P O}_{4} .2 \mathbf{H}_{2} \mathbf{O}$ & Ca(OH) \\
\hline HA 1.1 & $0.000(0)$ & $1.548(0.010)$ & $1.219(0.016)$ \\
\hline HA 1.2 & $0.500\left(1.25 \times 10^{-7}\right)$ & $1.548(0.010)$ & $1.219(0.016)$ \\
\hline HA 1.3 & $1.000\left(2.50 \times 10^{-7}\right)$ & $1.548(0.010)$ & $1.219(0.016)$ \\
\hline HA 1.4 & $1.500\left(3.75 \times 10^{-7}\right)$ & $1.548(0.010)$ & $1.219(0.016)$ \\
\hline HA 1.5 & $2.000\left(5.00 \times 10^{-7}\right)$ & $1.548(0.010)$ & $1.219(0.016)$ \\
\hline
\end{tabular}

Table 2. Amounts of starting materials used in the synthesis of HA samples of series 02

\begin{tabular}{|c|c|c|c|}
\hline \multirow{2}{*}{ Sample Name } & \multicolumn{3}{|c|}{ Weight (moles) / g } \\
\cline { 2 - 4 } & $\begin{array}{c}\text { PEO } \\
\text { of 6,000,000 Da }\end{array}$ & $\mathbf{N a H}_{\mathbf{2}} \mathbf{P O}_{4} .2 \mathbf{H}_{2} \mathbf{O}$ & $\mathbf{C a}(\mathbf{O H})_{2}$ \\
\hline HA 2.1 & $0.000(0)$ & $1.548(0.010)$ & $1.219(0.016)$ \\
\hline HA 2.2 & $0.500\left(8.3 \times 10^{-8}\right)$ & $1.548(0.010)$ & $1.219(0.016)$ \\
\hline HA 2.3 & $1.000\left(16.6 \times 10^{-8}\right)$ & $1.548(0.010)$ & $1.219(0.016)$ \\
\hline HA 2.4 & $1.500\left(24.9 \times 10^{-8}\right)$ & $1.548(0.010)$ & $1.219(0.016)$ \\
\hline HA 2.5 & $2.000\left(33.2 \times 10^{-8}\right)$ & $1.548(0.010)$ & $1.219(0.016)$ \\
\hline
\end{tabular}



mechanism

were recorded using JASCO FTIR 410 spectrophotometer with 256 accumulations at $4 \mathrm{~cm}^{-1}$ resolution. $1 \mathrm{~cm}$ diameter constant-weight pellets (dispersed in $\mathrm{KBr}$ as pellets in the mass ratio of sample: $\mathrm{KBr}=$ 1:10) was used to record IR absorbance spectra.

Scanning Electronic Microscopic (SEM) studies were done by JEOL JSM-6320F Field Emission type scanning electron microscope (Shizuoka University, Japan), Hitachi SU6600 Analytical Variable Pressure Field Emission Scanning Electron Microscope (Shizuoka University, Japan) and ZEISS EVO LS15 Scanning Electron Microscope (University of Peradeniya, Sri Lanka). Samples were sputter-coated with gold by Quorum SE 7620 sputter coater (University of Peradeniya, Sri Lanka) before examination under the SEM.

\section{Results and discussions}

The XRD patterns of all the prepared samples (Figures 2-3) show diffraction peaks $(002,102,211,112,300,310,222,213,004$ etc) in good agreement with the standard for $\mathrm{HA}\left(\mathrm{Ca}_{10}\left(\mathrm{PO}_{4}\right)_{6}(\mathrm{OH})_{2}\right)$ compiled by the Joint Committee on Powder Diffraction Standards (JCPDS Card No 09-0432). There are no characteristic peaks of impurities, such as calcium oxide (CaO, Card No 37-1497) and $\beta$-tricalcium phosphate ( $\beta$-TCP, $\mathrm{Ca}_{3}\left(\mathrm{PO}_{4}\right)_{2}$, Card No 09-0169), indicating that phase pure HA has been prepared under the above described experimental conditions. The XRD patterns of series 01 and series 02 show sharper peaks, and hence all the prepared samples are crystalline. The full width at half maximum of (002) reflection is used to calculate the mean crystallite size using the Debye-Scherrer equation (Table 3 ).

A decrease in particle size could be observed upon increasing the polymer content in both series of HA (Table 3). Series 01 cannot be compared with series 02 as the molar proportions are higher in the sample series 01 . But even with higher molar proportions, lower molecular weight polymer could prepare similar sized or smaller size particles indicating the lower molecular weight of PEO favours smaller particle sizes.

The phase composition was also confirmed by FTIR analysis (Figure 4). The $472 \mathrm{~cm}^{-1}$ band, resulted from the $v_{2}$ phosphate mode [18]. The bands at 563, $601 \mathrm{~cm}^{-1}$ were derived from the $v_{4}$ bending vibration of $\mathrm{P}-\mathrm{O}$ mode and $966 \mathrm{~cm}^{-1}$ bands resulted from the $v_{1}$ symmetric P-O stretching vibration. The larger peak at $1456 \mathrm{~cm}^{-1}$ and a smaller peak at $864 \mathrm{~cm}^{-1}$ were attributed to the $\mathrm{CO}_{3}^{2-}$ group and may have been due to the presence of $\mathrm{CO}_{2}$ during the synthesis. This further indicates the substitution of $\mathrm{CO}_{3}{ }^{2-}$ for the $\mathrm{PO}_{4}^{3-}$ position in the HA lattice, resulting in. B-type carbonates [19]. The strong band at $1032 \mathrm{~cm}^{-1}$ and 1099 $\mathrm{cm}^{-1}$ were also assigned to the $\mathrm{P}-\mathrm{O}$ stretching vibrations of $\mathrm{PO}_{4}^{3-}$. The broad band at $3100-3500 \mathrm{~cm}^{-1}$ corresponds to adsorbed water while the band at $3566 \mathrm{~cm}^{-1}$ corresponds to the structural $\mathrm{OH}^{-}$. The peak is very weak due to an overlap with the broad strong peak of adsorbed water molecules $[8,11,20,21]$.

The FTIR spectra of HA samples prepared with and without PEO look similar to each other. There are no peaks for $\mathrm{C}-\mathrm{H}$ vibrations around

Table 3. The calculated particle sizes of HA samples of series 01 and 02

\begin{tabular}{|c|c|c|}
\hline \multirow{2}{*}{ Sample Name } & \multicolumn{2}{|c|}{ Particle Size / nm } \\
\cline { 2 - 3 } & Series (S) 01 & Series(S) 02 \\
\hline HA S.1 & 41 & 41 \\
\hline HA S.2 & 40 & 40 \\
\hline HA S.3 & 38 & 39 \\
\hline HA S. 4 & 37 & 39 \\
\hline HA S.5 & 33 & 38 \\
\hline
\end{tabular}

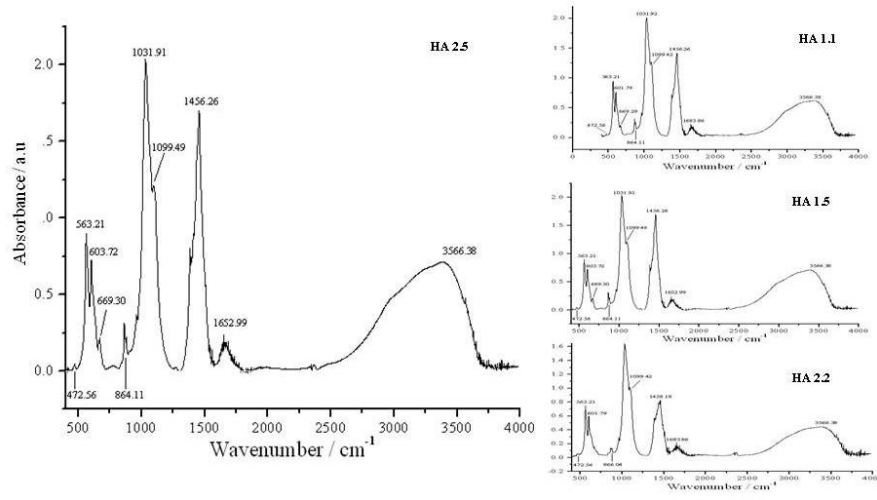

Figure 4. FTIR spectra of HA of series 01 and 02

3010-3090 $\mathrm{cm}^{-1}$ and no peaks for C-O (ether) vibrations around 1180 $1300 \mathrm{~cm}^{-1}$, indicating that pure HA crystallites without PEO impurities were prepared from the above-mentioned synthesis. Thus, FTIR spectrum shows that the nanoparticles obtained are predominantly hydroxyapatite with a minor carbonate impurity. $\mathrm{CO}_{3}^{2-}$ substitution may be due to the reactive absorption of atmospheric $\mathrm{CO}_{2}$ by the alkaline solution during the slurry preparation.

Polymeric materials often serve as stabilizers for metal colloids, preventing their agglomeration and precipitation by steric stabilization. Due to the ether oxygen groups with rich electrons in its chain, PEO is able to form complexes with metal cations and enhance the homogeneous mixing of the metal cation. Metal cations can easily disperse in a solution at the molecular level because of the interaction within and random arrangement of the polymer chain. This may be the reason for this one-step approach to yield HA nanoparticles that are crystallized, highly dispersed and have similar particle size. In addition, the polymer-assisted self-assembly can be a formation mechanism for the nano-rod like assemblies consisting of HA nanoparticles of a size below $20 \mathrm{~nm}$. During the initial stage, a large number of fine nanoparticles in spherical shape will be formed after the initial nucleation.

XRD, FTIR of HA prepared in blank samples (1.1 and 2.1) indicate the nanoparticles are predominantly $\mathrm{HA}$ with a minor carbonate impurity and SEM image shows those nanoparticles are spherical in shape (Figure 5). However, Rod-like assemblies of HA spherical nanoparticles of $\sim 20 \mathrm{~nm}$ with nanopores could be obtained in the polymer assisted synthesis (Figure 6).

According to the well-known Ostwald ripening mechanism, initially formed small crystals in a system slowly disappear except for a few that grow larger, i.e. smaller crystals act as "nutrients" for the bigger crystals. This is a spontaneous process because larger crystals are more energetically favoured. Formation of many small crystals is a kinetically favoured process while the formation of large crystals is a thermodynamically favoured process [15,22].

Taking into account the hydroxyapatite lattice parameters and its symmetry, it's unit cells will most likely be arranged along the c-axis [23]. However, in this case, it is likely that the use of PEO restricts growth along the (001) direction. With the presence of -C-O-Cgroups in the PEO polymer backbone, it may be able to coordinate with inorganic ions, most likely $\mathrm{Ca}^{2+}$ which is mostly found in the (001) face, leading to a lower surface energy and restriction of growth along the (001) direction.[15,24,25] After assisting the HA synthesis, PEO may be washed off during the washing steps with distilled water and ethanol. So that the space occupied by the polymer as the matrix may lead to the 


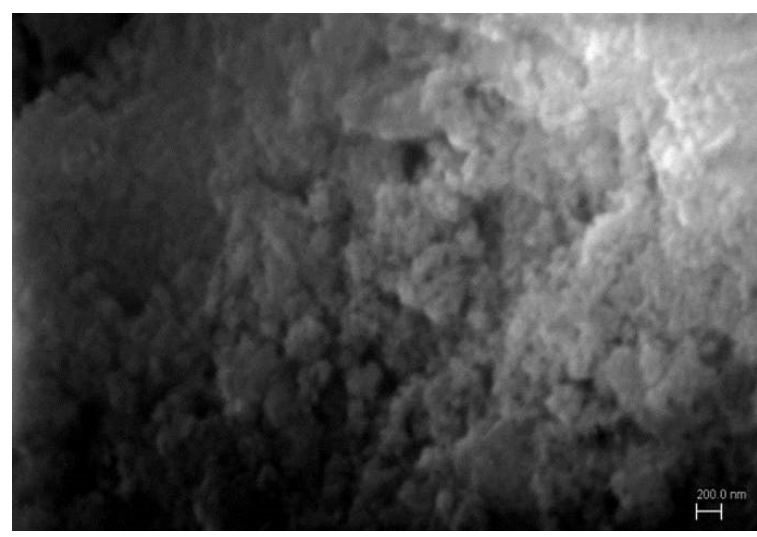

Figure 5. SEM image of HA 2.1
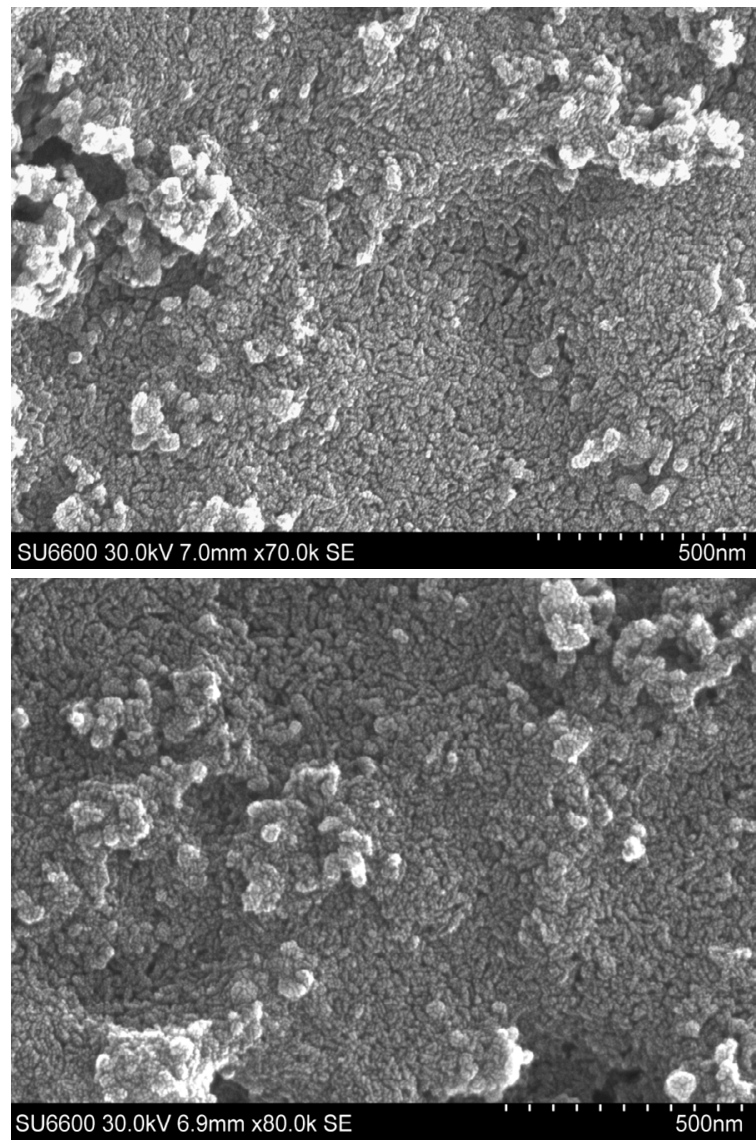

Figure 6. SEM images of HA 2.3 at different locations

appearance of nanopores as well as the homogeneous distribution of HA nanoparticles. After removing the polymer by washing steps, (001) face of HA crystals may have a higher surface energy, leading to a grouping of nano-HA particles into the rod-shaped assemblies as shown in the Figure 6. Mechanism of formation is illustrated in Figure 7.

The mechanical properties of HA samples of series 02 were tested using rectangular bars with a dimension of $(40 \mathrm{~mm} \times 5 \mathrm{~mm} \times 5 \mathrm{~mm})$, using the universal mechanical testing machine with 4-point bending at a crosshead speed of $4.075 \times 10^{-3} \mathrm{mms}^{-1}$.

According to the results obtained in Table 4, with increasing polymer content, Young's modulus can be increased. But a clear variation of the flexural strength (MOR) cannot be observed. However, Young's modulus and Flexural strength are higher in the blank samples (HA 2.1) than that of HA samples synthesized using PEO. This may be due to the higher porosity appeared in the samples and self-assembly of spherical nanoparticles into rod-shaped structures of HA after the removal of PEO. However, Young's modulus of HA samples is comparable with Young's modulus of cortical bone. But the flexural strength of synthesized HA samples is only comparable with the flexural strength of the cancellous bone. The nanostructured materials have exhibited some unique properties that normal microstructured materials do not have, such as high hardness and low wear rate suitable for engineering materials. For hydroxyapatite, the nanomaterial will have extremely high surface area $[8,11,26]$. Since the atoms in the surface layer have an un-saturated atomic bond, nano-HA exhibits a high bioactivity, which accelerates the early stage bone growth and tissue healing. Cell adhesion was higher on the surface of HA nanostructure that consisted of fine and uniform sized granules [8]. In another study, the ability of human osteoblastlike cells to grow within the HA foam was investigated in vitro using human osteosarcoma cells seeded directly on the ceramic surfaces to determine the bioactivity, where a synthesized porous HA showed there was an increase in cell proliferation and retention of phenotype for the period studied [5]. Therefore, the synthesized HA may act as an excellent biocompatible material that can be used in orthopaedics due to its uniform morphology, highly disperse particles of nano size and nanoporosity. In addition, disadvantages of using biometals, such as stress-shielding effect and limited osteointegration can be avoided by

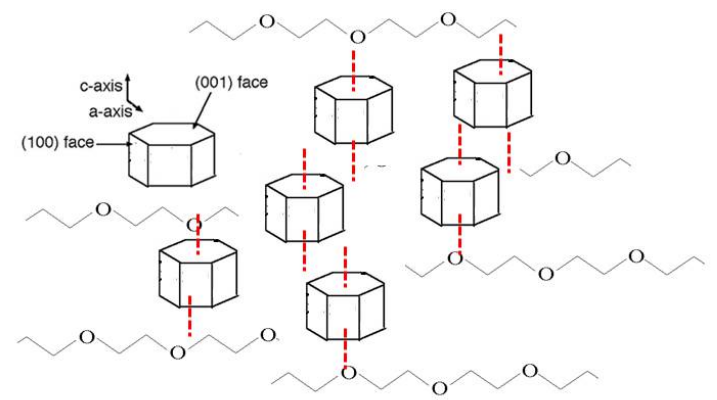

Step 01: Coordination of-C-O-C-groups in the PEO backbone with $\mathrm{Ca}^{2+}$ leading to a lower surface energy and restriction of growth along the (001) direction.

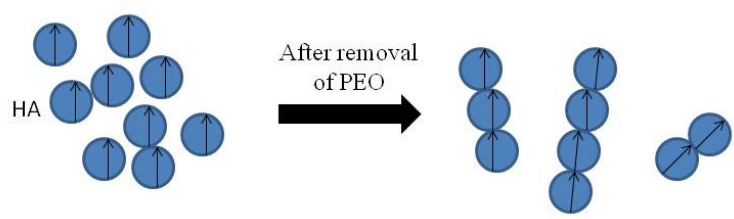

Step 02: (001) face of HA crystals with higher surface energy, leading to a grouping of nano HA particles into the rod shaped assemblies

Figure 7. Mechanism of formation of HA nano-assemblies during polymer assisted synthesis

Table 4. Mechanical properties of HA of series 02 and bone

\begin{tabular}{|c|c|c|}
\hline Sample & Young's Modulus/ GPa & MOR/ MPa \\
\hline 2.1 & 19.1 & 0.971 \\
\hline 2.2 & 10.6 & 0.924 \\
\hline 2.3 & 12.4 & 1.302 \\
\hline 2.4 & 16.5 & 1.012 \\
\hline 2.5 & 16.2 & 0.803 \\
\hline Cortical bone & $10-22$ & $130-180$ \\
\hline Cancellous bone & $0.05-1$ & $2-25$ \\
\hline
\end{tabular}



mechanism

using the synthesized nano-HA as its Young's modulus is comparable with that of bone and due to its expected osteointegration ability.

\section{Conclusions}

Rod-like assemblies of HA spherical nanoparticles of $\sim 20 \mathrm{~nm}$ with nanopores can be obtained by a novel polymer assisted hydrothermal synthesis using $\mathrm{Ca}(\mathrm{OH})_{2}$ and $\mathrm{NaH}_{2} \mathrm{PO}_{4} \cdot 2 \mathrm{H}_{2} \mathrm{O}$ precursors with the polymer PEO, in two different sizes without controlling the $\mathrm{pH}$ manually. With increasing the PEO content in the precursor solution, particle size can be decreased, and Young's modulus can be increased. However, Young's modulus of HA synthesized without using PEO is higher than that of HA synthesized with the use of PEO in the concentration range of PEO used in the experiment. But Young's modulus of HA synthesized using PEO are comparable with that of natural cortical bone, so that it can be used in biomedical applications. In addition, synthesized HA may act as an excellent biocompatible material that can be used in orthopaedics due to its uniform morphology, highly disperse particles of nano size and nanoporosity.

\section{Acknowledgement}

We acknowledge the Sri Lanka National Science Foundation for the financial support (Research Grant No: RG/2007/FR/08).

\section{References}

1. Weiner S, Traub W (1992) Bone structure: from angstroms to microns. FASEB $J$ 6: 879-885. [Crossref]

2. Alves NM, Leonor IB, Azevedo HS, Reis RL, Mano JF (2010) Designing biomaterials based on biomineralization of bone, J Mater Chem. 20: 2911.

3. Zhang Z, Yang Y, Ong JL, Zhang YY, Ong JL (2006) Nano-Hydroxyapatite for Biomedical Applications, in: Tissue Eng. Artif. Organs, 3rd ed., Taylor and Francis Group, LLC, 2006: pp. 24-1-24-11.

4. Elliott JC, Wilson RM, Dowker SEP (2002) Apatite structures, Adv. X-Ray Anal. 45 (2002) 172-181.

5. Herath HM, Di Silvio L, Evans JR (2005), Porous hydroxyapatite ceramics for tissue engineering., J. Appl. Biomater. Biomech. 3: 192-198. [Crossref]

6. Krisanapiboon A, Buranapanitkit B, Oungbho K (2006) Biocompatability of hydroxyapatite composite as a local drug delivery system., J. Orthop. Surg. (Hong Kong). 14: 315-318. [Crossref]

7. Alcaide M, Serrano MC, Pagani R, Sánchez-Salcedo S, Vallet-Regí M (2009) Biocompatibility markers for the study of interactions between osteoblasts and composite biomaterials, Biomaterials. 30: 45-51.
8. Manoj M, Subbiah R, Mangalaraj D, Ponpandian N, Viswanathan C, et al. (2015) Influence of Growth Parameters on the Formation of Hydroxyapatite ( HAp ) Nanostructures and Their Cell Viability Studies, 1-11.

9. Khalil KA, Almajid AA, Soliman MS (2011) Effect of Hydroxide Ion Concentration on the Morphology of the Hydroxyapatite Nanorods Synthesized Using Electrophoretic Deposition, Mater. Sci. Appl. 2: 105-110.

10. Rodríguez-Lorenzo LM, Vallet-Regí M, (2000) Controlled crystallization of calcium phosphate apatites, Chem. Mater. 12: 2460-2465.

11. Klinkaewnarong J, Maensiri S (2010) Nanocrystalline hydroxyapatite powders by a polymerized complex method, Chiang Mai J. Sci. 37: 243-251.

12. Nayar S, Sinha MK, Basu D, Sinha A (2006) Synthesis and sintering of biomimetic hydroxyapatite nanoparticles for biomedical applications, J Mater Sci Mater Med 17: 1063-1068. [Crossref]

13. Tseng YH, Kuo CS, Li YY, Huang CP, (2009) Polymer-assisted synthesis of hydroxyapatite nanoparticle, Mater. Sci. Eng. C. 29: 819-822.

14. Vaidhyanathan B, Rao KJ, (1996) Rapid microwave assisted synthesis of hydroxyapatite, Bull. Mater. Sci. 19: 1163-1165.

15. Nathanael, AJ Han, SS, Oh TH, (2013) Polymer-Assisted Hydrothermal Synthesis of Hierarchically Arranged Hydroxyapatite Nanoceramic, J. Nanomater. 2013: 1-8.

16. Li Z, Xiong Y, Xie Y (2003) Selected-control synthesis of ZnO nanowires and nanorods via a PEG-assisted route. Inorg Chem 42: 8105-8109. [Crossref]

17. B.Z. et al. Jeon SH, Xu P (2011) Polymer-assisted preparation of metal nanoparticles with controlled size and morphology, J. Mater. Chem. 21: 2550-2554.

18. Yingjun W, Zhang S, Wei K, Zhao N, Chen J, et al. (2006) Hydrothermal synthesis of hydroxyapatite nanopowders using cationic surfactant as a template., Mater. Lett. 60 : 1484-1487.

19. Cao M, Wang Y, Guo C, Qi Y, Hu C (2004) Preparation of ultrahigh-aspect-ratio hydroxyapatite nanofibers in reverse micelles under hydrothermal conditions. Langmuir. 20: 4784-4786. [Crossref]

20. J.C. and X.W. Y. Wang, S. Zhang, K. Wei, N. Zhao, (2006) Hydrothermal Synthesis of hydroxyapatite nano powders using cationic surfactant as a template., Mater. Lett. 60: $1484-1487$.

21. Murugan R, Ramakrishna S, (2007) Development of cell-responsive nanophase hydroxyapatite for tissue engineering, Am. J. Biochem. Biotechnol. 3: 118-124.

22. Rodriguez-Lorenzo LM, Vallet-Regi M (2000) Controlled crystallization of calcium phosphate apatites, Chem. Mater. 12: 2460-2465.

23. Vallet-Regí M, Ceramics for medical applications, J Chem Soc Dalt Trans. (2001) 97-108.

24. Mullin JW, Crystallization, 4th ed., Butterworth-Heinemann, Oxford, 2001.

25. Jones AG, Crystallization Process Systems, 1st ed., Butterworth-Heinemann, Oxford, 2002.

26. Lakes R, (1993) Materials with structural hierarchy, Nature. 361: 511-515.

Copyright: $(2018$ Gamagedara TP. This is an open-access article distributed under the terms of the Creative Commons Attribution License, which permits unrestricted use, distribution, and reproduction in any medium, provided the original author and source are credited. 